\title{
Prevalence of and Reasons for Patients Leaving Against Medical Advice from Paediatric Wards in Oman
}

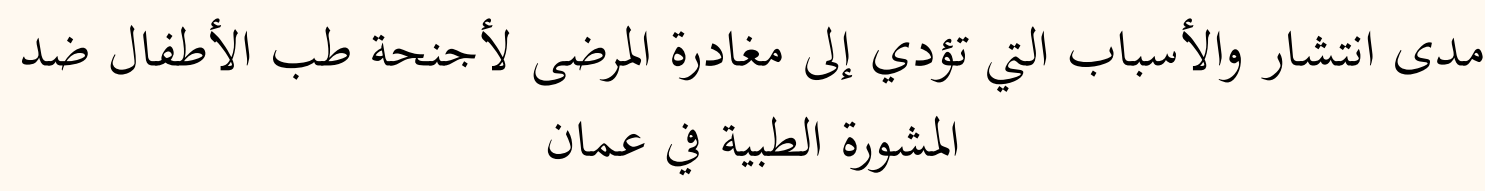

$$
\text { محمد الغافري، عبداله البلوشي، أحمد القاسمي }
$$

ABSTRAC T: The objective of this study was to determine the prevalence of and reasons for patients leaving against medical advice (LAMA) in a paediatric setting in Oman. This retrospective study was carried out between January 2007 and December 2009 and assessed patients who left the paediatric wards at the Royal Hospital, Muscat, Oman, against medical advice. Of 11,482 regular discharges, there were 183 cases of LAMA (prevalence: 1.6\%). Dissatisfaction with treatment and a desire to seek a second opinion were collectively the most cited reasons for LAMA according to data from the hospital's electronic system (27.9\%) and telephone conversations with patients' parents $(55.0 \%)$. No reasons for LAMA were documented in the hospital's electronic system for 109 patients (59.6\%). The low observed prevalence of LAMA suggests good medical practice at the Royal Hospital. This study indicates the need for thorough documentation of all LAMA cases to ensure the availability of high-quality data for healthcare workers involved in preventing LAMA.

Keywords: Children; Patient Discharge; Documentation; Oman.

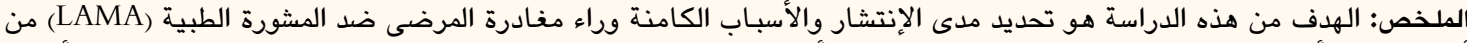

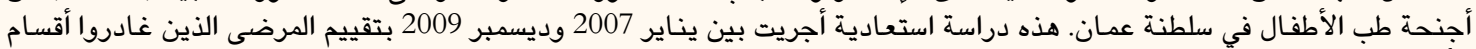

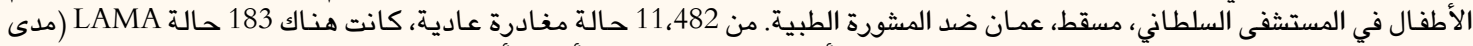

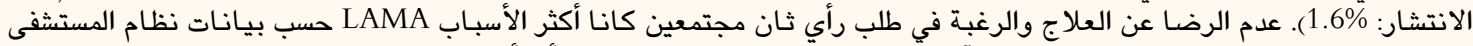

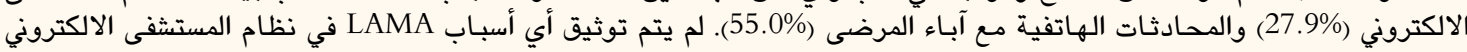

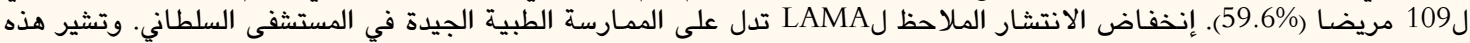

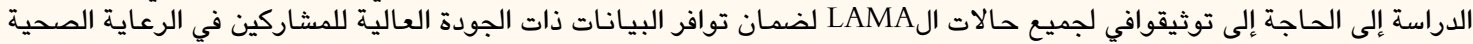
الساعين لمنع LAMA.

مفتاح الكلمات: الأطفال؛ تخريج المريض؛ التوثيق؛ عمان.

L EAVING AGAINST MEDICAL ADVICE (LAMA) IS a term that describes the discharge of a patient from a hospital without the agreement of the treating doctor, usually at their own request or that of their caregivers in the case of paediatric patients. LAMA has been documented in numerous healthcare settings and accounts for $1-26 \%$ of the discharges of general medical patients worldwide. ${ }^{1-4}$ When patients choose to leave the hospital before the recommendation of a treating physician, the consequences can involve risks associated with inadequately treated medical conditions, the need for readmission and sometimes loss of life. ${ }^{4-7}$ In many LAMA cases, a patient is not medically fit to be discharged; however, the treating team are not able to oppose the wishes of a patient or their caregiver. Feeling better or personal/financial obligations are some of the reasons for LAMA reported in the literature. ${ }^{8}$ Generally, once a patient or their family insists on LAMA, a form is completed which must be signed by both the patient/ caregiver and the responsible physician. The reason for the discharge is usually then recorded in the hospital's electronic system by the physician. The signed LAMA form exists to protect the treating team and their medical institution from legal liability; good clinical practice and thorough documentation remain the best legal protection in cases of LAMA. ${ }^{9}$ In Oman, hospital staff can obtain an order from the General Prosecutor to refuse to discharge children from hospital before the completion of treatment. ${ }^{10}$

For children, the problem of LAMA has been addressed in many studies around the world but rarely in countries in the Middle Eastern region. ${ }^{1-3}$ The 
Table 1: Reasons for leaving against medical advice among paediatric patients in the Royal Hospital, Muscat, Oman, according to hospital electronic records $(\mathrm{N}=183)$

$\begin{array}{lc}\text { Reason for LAMA } & \text { n (\%) } \\ \text { Dissatisfaction with treatment/care } & 24(13.1) \\ \text { Social issues } & 20(10.9) \\ \text { Seeking a second opinion } & 27(14.8) \\ \text { Financial issues } & 3(1.6) \\ \text { No documentation } & 109(59.6) \\ \text { LAMA = leaving against medical advice. }\end{array}$

objectives of this study were to determine the prevalence of LAMA among children from the paediatric wards at the Royal Hospital in Muscat, Oman, and to examine the characteristics of these patients and the reasons for their discharge against medical advice. The Royal Hospital is a tertiary teaching hospital which admits patients from all regions of Oman; it has three general paediatric and subspecialty wards.

\section{Methods}

This retrospective study was conducted from January 2007 to December 2009. Clinical and patient data were collected from the electronic hospital information system. Manually-filed LAMA forms were also reviewed in order to obtain additional information. The age of the patients, time of LAMA (either during official working hours from 07:30 to 14:30 or during on-call hours from 14:30 to 07:30 the next day, weekdays or at the weekend), length of hospital stay and presence of documented discussion with caregivers regarding LAMA were reviewed. Data on the designated counselling physician (i.e. consultant, registrar, resident or intern), the presence or absence of a follow-up appointment and the reasons for LAMA if mentioned in the discharge notes or the LAMA form were also collected.

Reasons for LAMA were categorised as dissatisfaction with treatment, the desire to seek a second opinion and social and/or financial reasons. The social reasons included unavailability of a caregiver for other children at home or other personal issues that were not disclosed by the patients' parents. The patients' diagnoses on discharge were also recorded and their diagnoses were categorised into purely acute conditions versus conditions attributed to pre-existing comorbidities (chronic conditions). In cases where the reason for LAMA was missing, the families were contacted by telephone in order to ascertain the reason they discharged their child against medical advice.
Table 2: Reasons for leaving against medical advice among paediatric patients in the Royal Hospital, Muscat, Oman, according to follow-up telephone interviews $(\mathrm{N}=109)$

$\begin{array}{lc}\text { Reasons for LAMA } & \mathbf{n}(\%) \\ \text { Dissatisfaction with treatment/care } & 17(15.6) \\ \text { Social issues } & 36(33.0) \\ \text { Seeking a second opinion } & 43(39.4) \\ \text { Financial issues } & 3(2.8) \\ \text { No reply } & 10(9.2) \\ \text { LAMA = leaving against medical advice. } & \end{array}$

Data processing and analysis were carried out using the Statistical Package for the Social Sciences (SPSS), Version 18 (IBM Corp., Chicago, Illinois, USA). In addition to descriptive statistics, hypothesis testing was carried out using the Student's t-test to make comparisons and Pearson's Chi-squared analysis to test for independence. Pearson's correlation coefficient was utilised to examine the relationships between relevant variables. The probability of a type two error was set at $5 \%$.

Ethical approval for this study was obtained from the Medical Ethics \& Scientific Research Committee of the Royal Hospital (MESRC \#6).

\section{Results}

Of the 11,482 discharges from the hospital's paediatric wards during the study period, 183 children left the hospital against medical advice, resulting in a LAMA prevalence of $1.6 \%$. A total of 74 patients $(40.4 \%)$ were $<1$ year old, 75 patients $(41.0 \%)$ were $1-5$ years old and 34 patients $(18.6 \%)$ were $>5$ years old. The length of stay ranged from 1-34 days with a mean of four days; 58 patients $(31.7 \%)$ stayed in the hospital for one day, 73 (39.9\%) stayed 2-5 days and 52 patients (28.4\%) stayed for $>5$ days.

In terms of diagnosis at discharge, 81 patients (44.3\%) had only acute conditions, while 102 patients (55.7\%) had chronic conditions. There was no statistically significant difference in the frequency of LAMA between these groups. Counselling on LAMA was undertaken by physicians for the families of 172 patients (94.0\%); the counselling designation was missing in 11 cases (6.0\%). Of those who underwent counselling, 29 families (16.9\%) being counselled by consultants, $98(57.0 \%)$ by registrars, $27(15.7 \%)$ by residents and 18 (10.5\%) by interns.

A total of 160 patients (87.4\%) were discharged during official working hours while the remaining 23 patients (12.6\%) were discharged during. Only 39 
patients (21.3\%) were discharged in the morning while 144 (78.7\%) were discharged during evening hours. Follow-up appointments were made for 153 patients (83.6\%) while no appointments were made for the remaining 30 patients (16.4\%).

According to the hospital's electronic system, a desire to seek a second opinion and dissatisfaction with treatment/care were the most cited reasons for LAMA ( $14.8 \%$ and $13.1 \%$, respectively) [Table 1 ]. A total of 109 patients (59.6\%) had no electronic documentation regarding their reasons for LAMA. The parents of these patients were contacted 1-4 years after LAMA. Table 2 shows that seeking a second opinion followed by social issues were the most cited reasons for LAMA among these 109 patients (39.4\% and 33.0\%, respectively).

\section{Discussion}

In this study, the LAMA prevalence was found to conform to reported rates in the literature; Okoromah et al. and Hong et al. reported a LAMA prevalence of $1.2 \%$ and $2 \%$ in Nigeria and Singapore, respectively. ${ }^{1,11}$ In contrast, Al-Sadoon et al. and Abdulateef et al. reported a LAMA prevalence of only $0.32 \%$ and $0.11 \%$ in Oman and Qatar, respectively. ${ }^{12,13}$ The setting of the latter study was different from other studies as it was conducted in a paediatric emergency centre within the ideal observation period of 48 hours. ${ }^{13}$ Al-Turkistani reported a LAMA prevalence of $1.6 \%$ in a neonatal intensive care unit at a university hospital in Saudi Arabia. ${ }^{14}$ Abd El Malek et al. noted a surprisingly high prevalence of LAMA (8.49\%) in a recent study carried out in Kuwait. ${ }^{15}$

In the current study, LAMA was more common for infants under one year of age; a similar finding was reported by Al-Sadoon et al. $(\mathrm{n}=24 ; 63.2 \%) .{ }^{12}$ Comparable findings were also reported in other studies which could be partly attributed to the large number of cases admitted from this age group. ${ }^{11,16}$ In addition, subtle clinical presentations among infants can put them at a higher risk of being admitted for further care. The mean length of hospital stay in the present study was slightly longer compared to that reported by a previous study (3.1 days). ${ }^{4}$ Moreover, almost a third of patients in the current study stayed for only one day. Al-Sadoon et al. reported a similar finding in their study $(\mathrm{n}=15 ; 39.5 \%) .{ }^{12}$ This finding might be attributed to non-critical reasons for admission, including diagnostic uncertainty. In addition, a short observation time in the emergency room along with the unavailability of a short-stay ward may have contributed to the LAMA cases that occurred during the first 24 hours after admission. Interestingly, the majority of patients were discharged during weekdays. On the other hand, Abd El Malek et al. reported a higher number of LAMA cases during the weekend; this was attributed to overcrowding and staff shortages during weekends. ${ }^{15}$

The majority of cases reviewed in the current study had poor documentation with regards to LAMA data, which conforms to reports from other studies. ${ }^{12,17}$ Al-Sadoon et al. reported poor documentation in $57.9 \%$ of LAMA cases. ${ }^{12}$ This finding illustrates the need for thorough recordkeeping in all LAMA cases to ensure that physicians, researchers, decision-makers and healthcare planners have the information they require in order to reduce the prevalence of LAMA.

According to the hospital electronic records assessed in the current study, dissatisfaction with treatment and the desire to seek a second opinion were the most cited reasons for LAMA; these findings are similar to those of several other studies on LAMA. ${ }^{18,19}$ Dissatisfaction with treatment might be attributed to a parent's unwillingness for their child's case to be studied for teaching purposes or due to frequent blood sampling or prolonged hospitalisation. These reasons were also the most commonly cited during telephone interviews with the parents in cases without electronic documentation. Social reasons for LAMA were reported by a third of the parents, which could indicate a lack of willingness by the families to fully disclose their reasons for LAMA during the telephone interviews. These reasons might include a lack of care for other children at home or work commitments. Since medical services are free for Omani citizens, financial reasons represented a very small proportion of LAMA cases. As such, financial reasons were only reported by expatriate patients without medical insurance.

Although it was not statistically significant, a greater proportion of the study population with chronic medical problems were discharged against medical advice than those with non-chronic conditions. The higher frequency of LAMA among this group could be attributed to parents of children with chronic conditions being accustomed to caring for them at home with oral medications. The majority of LAMA cases in the current study occurred during on-call hours. This was expected since, in Oman, fathers are anecdotally the ones to decide whether to discharge their children against medical advice, and the majority of fathers arrive at the hospital in the evening after official working hours. Another reason for this result could be the absence of in-house consultants after normal daytime working hours who could potentially counsel patients' parents in order to minimise LAMA cases. Interestingly, few of the parents who chose to 
discharge their children in the current study were counselled by consultants. This strongly suggests the importance of proper communication between physicians and parents. ${ }^{20}$

Limitations in the current study include a lack of a control group to compare illnesses between patients who were discharged with the recommendation of the physician and those who left against medical advice; a lack of follow-up of the discharged children; unavailability of documentation in many cases; the interval between the telephone interviews and the LAMA case which may have adversely affected the results; and a relatively small sample size leading to an inability to generalise the results. Further studies on cases of paediatric LAMA are needed, particularly multi-centre studies that include a comparison of outcomes between LAMA cases and those with usual discharge decisions.

\section{Conclusion}

This study sought to identify the reasons for LAMA among paediatric patients at the Royal Hospital. The results indicate that more effective communication between the treating team and families, along with early interventions, are needed in order to minimise LAMA. There is a need for thorough documentation of all LAMA cases to ensure the availability of highquality data for physicians, researchers, decisionmakers and healthcare planners. Further studies are recommended to assess the outcomes for children who leave paediatric wards before the completion of their treatment.

\section{CONFLICT OF INTEREST}

The authors declare no conflicts of interest.

\section{References}

1. Okoromah CN, Egri-Qkwaji MT. Profile of and control measures for paediatric discharges against medical advice. Niger Postgrad Med J 2004; 11:21-5.

2. Ibrahim SA, Kwoh CK, Krishnan E. Factors associated with patients who leave acute-care hospitals against medical advice. Am J Public Health 2007; 97:2204-8. doi: 10.2105/ AJPH.2006.100164

3. Mohseni Saravi B, Reza Zadeh E, Siamian H, Yahghoobian M. Discharge against medical advice in the pediatric wards in Boo-ali Sina Hospital, Sari, Iran 2010. Acta Inform Med 2013. 21:253-6. doi: 10.5455/aim.2013.21.253-256.
4. Onyiriuka AN. Discharge of hospitalized under-fives against medical advice in Benin City, Nigeria. Niger J Clin Pract 2007; $10: 200-4$.

5. Weingart SN, Davis RB, Phillips RS. Patients discharged against medical advice from a general medicine service. J Gen Intern Med 1998; 13:568-71. doi: 10.1046/j.1525-1497.1998.00169.x.

6. Hwang SW, Li J, Gupta R, Chien V, Martin RE. What happens to patients who leave hospital against medical advice? CMAJ 2003; 168:417-20.

7. Aliyu ZY. Discharge against medical advice: Sociodemographic, clinical and financial perspectives. Int J Clin Pract 2002; 56:325-7.

8. Roodpeyma S, Hoseyni SAE. Discharge of children from hospital against medical advice. World J Pediatr 2010; 6:353-6. doi: 10.1007/s12519-010-0202-3.

9. Devitt PI, Devitt AC, Dewan M. An examination of whether discharging patients against medical advice protects physicians from malpractice charges. Psychiatr Serv 2000; 51:899-902. doi: 10.1176/appi.ps.51.7.899.

10. Oman Ministry of Legal Affairs. Royal Decree No. 22/2014 issuing the Children's Act. From: www.mola.gov.om/ officalgazette.aspx?page=4 Accessed: Sep 2015 .

11. Hong LE, Ling FC. Discharges of children from hospital against medical advice. J Singapore Paediatr Soc 1992; 34:34-8.

12. Al-Sadoon M, Al-Shamousi K. Discharge against medical advice among children in Oman: A university hospital experience. Sultan Qaboos Univ Med J 2013; 13:534-8. doi: $10.12816 / 0003312$

13. Abdulateef H, Al Amri M, Sayyed RF, Al Ansari K, Lariego G, Al Hammadi Z. Discharge against medical advice in a pediatric emergency center in the State of Qatar. J Emerg Med Trauma Acute Care 2012; 2012:4. doi: 10.5339/jemtac.2012.4.

14. Al-Turkistani HK. Discharge against medical advice from neonatal intensive care unit: 10 years' experience at a university hospital. J Fam Comm Med 2013; 20:113-15. doi: 10.4103/22308229.114774 .

15. Abd El Malek V, Alexander S, Al Anezi F. Discharge against medical advice among children admitted into pediatric wards at Al-Jahra Hospital, Kuwait. Kuwait Med J 2014; 46:28-31.

16. Nathoo KJ, Bannerman CH, Pirie DJ. Pattern of admission to the paediatric medical wards (1995 to 1996) at Harare Hospital, Zimbabwe. Cent Afr J Med 1999; 45:258-63.

17. Reinke DA, Walker M, Boslaugh S, Hodge D 3rd. Predictors of pediatric emergency patients discharged against medical advice. Clin Pediatr (Phila) 2009; 48:263-70. doi: 10.1177 /0009922808323109.

18. Onukwugha E, Saunders E, Mullins CD, Pradel FG, Zuckerman M, Weir MR. Reasons for discharges against medical advice: A qualitative study. Qual Saf Health Care 2010; 19:420-4. doi: 10.1136/bmjopen-2012-000902.

19. Macrohon BC. Pediatrician's perspectives on discharge against medical advice (DAMA) among pediatric patients: A qualitative study. BMC Pediatr 2012; 12:75. doi: 10.1186/1471-2431-12-75.

20. Targum SD, Capodanno AE, Hoffman HA, Foudraine C. An intervention to reduce the rate of hospital discharges against medical advice. Am J Psychiatry 1982; 139:657-9. doi: 10.1176/ ajp.139.5.657. 